\title{
Relationship between physical activity and sleep recommendations compliance and excess weight among school children from Temuco, Chile
}

\author{
Javiera Ceppi-Larraín, MSca, Damián Chandia-Poblete, $M S c^{b, c}$, \\ Nicolás Aguilar-Farías, Ph.D. ${ }^{a, c}$ and Jaime Cárcamo-Oyarzún, Ph.D. ${ }^{a, c}$
}

\begin{abstract}
Introduction. Given the importance of physical activity and sleep for health, different recommendations have been proposed for the pediatric population. The objective of this study was to determine the association between physical activity and sleep recommendations compliance and excess weight in school children from Temuco, Chile.

Population and methods. Physical activity and sleep weremeasured using ActiGraph wGT3X-BT ${ }^{\circledR}$ accelerometers. Excess weight was categorized on two categories: absence (normal weight) or presence (overweight or obesity) based on body mass index.
\end{abstract}

a. Department of Physical Education, Sports, and Recreation, Universidad de La Frontera, Temuco, Chile.

b. School of Public Health and Social Work, Queensland University of Technology, Queensland, Australia.

c. UFRO Actívate Research Group, Universidad de La Frontera, Temuco, Chile.

E-mail address: Jaime CárcamoOyarzún, M.D.: jaime.carcamo@ ufrontera.cl

Funding:

ANID Chile through projects FONDECYT 11160720 and FONDECYT 11170525.

Universidad de La Frontera. InES19 Free Investigators Program. Code FRO19101.

Conflict of interest: None.

Received: $12-3-2020$

Accepted: 5-2-2021

\section{INTRODUCTION}

The prevalence of excess weight in the pediatric population has experienced an evident increase in recent decades and is considered an epidemic affecting public health worldwide ${ }^{2}$ due to the non-communicable diseases accompanying it. ${ }^{3}$

Several studies indicate that lack of physical activity may be a major factor contributing to the prevalence of excess weight. ${ }^{4}$ This is a very concerning scenario because lack of physical activity and a sedentary behavior are prevalent in most countries, ${ }^{5}$ and school children usually spend long screen time periods compared to little time engaged in active play. ${ }^{6}$ Regular physical activity offers multiple benefits to the pediatric population. ${ }^{7}$ It reduces the risk for obesity, ${ }^{8}$ improves psychological health, increases self-esteem, and reduces stress. ${ }^{10}$ In addition, it promotes the development of perceived social competence, ${ }^{11}$ improves nervous system maturation, ${ }^{12}$ encourages motor competence, ${ }^{13}$ and helps to a better academic performance. ${ }^{14}$

Another emerging factor related to excess weight is the amount of sleep. ${ }^{15,16}$ It has been observed that the longer and more stable the amount of sleep, the less likely is for a child to develop metabolic disorders. ${ }^{17}$ In recent decades, children's sleep habits have evidenced a negative change compared to previous generations: the amount of sleep has reduced markedly. ${ }^{18}$

Given the importance of both physical activity and sleep in relation to child health and wellbeing, different recommendations have been proposed to have a healthy 
day (24 hours). These comprise a combination of amount of sleep, sedentary behavior (screen time), and light, moderate, and vigorous physical activity. ${ }^{19-21}$ The evidence in the Chilean school children population indicates a low compliance with recommendations in relation to sleep, ${ }^{22}$ screen time, ${ }^{23}$ and physical activity. ${ }^{24}$ Children and adults who do not meet daily physical activity and sleep recommendations may have a higher risk for excess weight. ${ }^{25}$ Considering the high incidence of excess weight in Chilean school children $^{26}$ and high levels of physical inactivity, ${ }^{24}$ the objective of this study is to determine the association between physical activity and sleep recommendations compliance and excess weight in school children from Temuco, Chile.

\section{POPULATION AND METHODS}

The sample was selected by convenience, using a non-probabilistic sampling, among children attending $5^{\text {th }}$ and $6^{\text {th }}$ grade at 5 primary schools corresponding to different socio-economic levels and geographic locations in the city of Temuco, Chile. The inclusion criterion was attending $5^{\text {th }}$ or $6^{\text {th }}$ grade of primary school; school children who did not complete all assessments (anthropometry and accelerometry) were excluded.

The sample size was estimated based on the following data: a) $3.7 \%$ of children were active based on an accelerometry from a previous study; ${ }^{22}$ b) 20 participants per cluster (school grade); c) $5 \%$ significance level; d) $5 \%$ absolute accuracy; and e) size effect of 1.3 based on Williamson et al. ${ }^{27}$ Therefore, a minimum of 200 participants (10 clusters or school classes) was estimated. Based on an $80 \%$ response, the final sample was made up of 240 participants.

The study protocol was approved by the Ethics Committee of Universidad de La Frontera (record no.122_17). Parents signed a consent, and school children gave their written assent to participate in the study voluntarily.

\section{Procedures}

Study participants were assessed by trained staff at their respective schools, during the Physical Education class, and completed a questionnaire with their sociodemographic information. Their weight and height were measured afterwards. Lastly, school children were instructed on how to use the accelerometers; the devices were delivered; and their correct placement was verified.

\section{Physical activity and amount of sleep}

Physical activity, sedentary behavior, and sleep were measured using ActiGraph wGT3X$\mathrm{BT}^{\circledR}$ accelerometers (ActiGraph, Pensacola, FL), which were procured through project Fondecyt 11170525, funded by the National Research Agency of Chile. Participants were asked to wear the accelerometer continuously for 7 days $^{28}$ and to take it off only during activities involving water (e.g., taking a shower). The accelerometer was placed on the right side, at the level of the waist, the midaxillary line, and the iliac crest.

Data were downloaded from the accelerometers in epochs of 60 seconds using the Actilife 6.13.4 ${ }^{\circledR}$ software (Pensacola, FL, USA). In this study, sedentary time, light physical activity time, moderate physical activity time, and vigorous physical activity time data were used, as expressed in minutes.

First, the non-wear time of the accelerometer was registered. The minimum number of data deemed valid was 4 days of use of at least 10 hours per day, including at least 1 day of the weekend. Then, the amount of sleep and the number of nocturnal awakenings across all business days were estimated using Sadeh's algorithm. ${ }^{29}$ Leaving out data about not use of the accelerometer and sleep, the times corresponding to sedentary behavior and physical activity at different levels were detected using the cut-off points proposed by Evenson. ${ }^{30}$ Participants were classified as being physically active if they did an average of 60 minutes of moderate to vigorous physical activity (3-5 metabolic equivalents [METs]) per day. ${ }^{21}$ In addition, the participants were considered to meet the sleep guidelines if they slept an average of 9-11 hours per day, based on Canadian guidelines. ${ }^{19}$

\section{Nutritional status}

Weight was assessed using a Tanita scale, model UM2204 (precision of $0.2 \mathrm{~kg}$, maximum weight of $136 \mathrm{~kg}$ ). It was measured with children barefoot and wearing sweatpants and a T-shirt. Height was measured using a Seca ${ }^{\circledR}$ stadiometer, model 217 (1 $\mathrm{mm}$ precision). The presence or absence of excess weight was determined based on body mass index (BMI), considering the parameters specific for each age and sex established by the World Health Organization. ${ }^{31}$

Normal weight $\left(<85^{\text {th }}\right.$ percentile) was defined as the "absence of excess weight," whereas overweight and obesity were categorized as the "presence of excess weight" (overweight: 
$\mathrm{BMI} \geq 85^{\text {th }}$ percentile and $<97^{\text {th }}$ percentile; obesity: $\mathrm{BMI} \geq 97^{\text {th }}$ percentile).

\section{Statistical analysis}

Descriptive statistics were estimated (measures of central tendency and absolute and relative frequencies). The Kolmogorov-Smirnov test was used to check if variables followed a normal distribution. The physical activity and sleep variables were compared by sex and compliance with recommendations based on the presence or absence of excess weight using Student's t test or the Mann-Whitney U test, as applicable. The association between compliance with physical activity and sleep recommendations and the presence of excess weight was determined based on a logistic regression analysis adjusted for age, sex, and sedentary behavior time. A value of $p<0.05$ was considered significant. The statistical analysis was performed with the IBM SPSS $25 \AA$ software.

\section{RESULTS}

A total of 183 school children participated in the study (Figure 1); of them, $54.1 \%$ were females; and participants were aged 9 to 13 years (mean $[\mathrm{M}]=10.95 ; \pm 1.07)$. Normal weight was observed in $45.9 \%$ (49.4\% of girls and $41.7 \%$ of boys) and excess weight, in $54.1 \%$ (50.6\% of girls and $58.3 \%$ of boys). Table 1 shows the anthropometric characteristics of school children by sex. No significant differences were observed in terms of age or anthropometric characteristics. Table 2 shows the descriptive results of physical activity and sleep of the sample by sex. Differences were noted in terms of moderate physical activity $(p=0.001)$ and the total of moderate and vigorous physical activity $(p=0.002)$, where boys were observed to be more active than girls. No significant differences were observed in sleep.

Table 3 shows the frequency of compliance with the recommendations for moderate and vigorous physical activity, amount of sleep, and both physical activity and sleeping among school children. As observed, the proportion of school children who met the moderate and vigorous physical activity and sleep recommendations was low. Compliance with both recommendations was non-significant.

Table 4 shows the sample's anthropometric, physical activity, and sleep characteristics based on the presence or absence of excess weight. In relation to physical activity, significant differences were observed in moderate activity $(p=0.013)$, vigorous activity $(p=0.002)$, and total moderate and vigorous physical activity $(p=0.004)$. School children who did not have excess weight were more active. In relation to sleep, significant differences were observed in the amount of sleep $(p=0.010)$ : school children who did not have excess weight slept more than those who did.

Lastly, according to the logistic regression. model, school children who did not meet the moderate and vigorous physical activity recommendation have a higher probability of having excess weight than those who do $(\mathrm{OR}=8.178 ; p=0.017)$. No association was

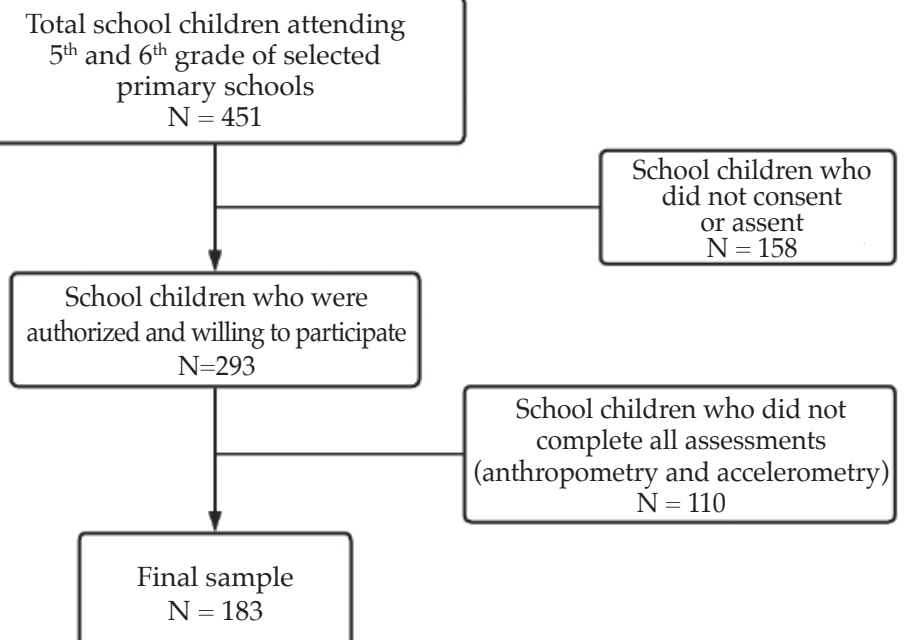


TABLE 1. Demographic characteristics by sex in a sample of school children from the city of Temuco, Chile $(n=183)$

\begin{tabular}{|c|c|c|c|c|c|c|c|}
\hline & & & \multicolumn{4}{|c|}{ Sex } & \\
\hline & \multicolumn{2}{|c|}{$\begin{array}{c}\text { Total } \\
(\mathrm{n}=183)\end{array}$} & \multicolumn{2}{|c|}{$\begin{array}{c}\text { Girls } \\
(\mathrm{n}=99)\end{array}$} & \multicolumn{2}{|c|}{$\begin{array}{c}\text { Boys } \\
(\mathrm{n}=84)\end{array}$} & \multirow[b]{2}{*}{$p$} \\
\hline & $\mathbf{M}$ & SD & $\mathbf{M}$ & SD & $\mathbf{M}$ & SD & \\
\hline Age (years) & 11.0 & 1.1 & 10.8 & 0.6 & 11.1 & 1.1 & 0.138 \\
\hline Weight $(\mathrm{kg})$ & 45.2 & 10.2 & 45.4 & 10.6 & 45.0 & 9.9 & 0.823 \\
\hline Height $(\mathrm{cm})$ & 145.0 & 7.3 & 145.5 & 7.3 & 144.4 & 7.4 & 0.390 \\
\hline BMI & 21.4 & 3.8 & 21.3 & 3.9 & 21.4 & 3.6 & 0.851 \\
\hline
\end{tabular}

BMI: body mass index.

TABLE 2. Descriptive data for physical activity and sleep by sex in a sample of school children from the city of Temuco, Chile $(n=183)$

\begin{tabular}{|c|c|c|c|c|c|c|c|}
\hline & & & \multicolumn{4}{|c|}{ Sex } & \multirow[b]{3}{*}{$p$} \\
\hline & \multicolumn{2}{|c|}{$\begin{array}{c}\text { Total } \\
(\mathrm{n}=183)\end{array}$} & \multicolumn{2}{|c|}{$\begin{array}{c}\text { Girls } \\
(\mathrm{n}=99)\end{array}$} & \multicolumn{2}{|c|}{$\begin{array}{c}\text { Boys } \\
(n=84)\end{array}$} & \\
\hline & $\mathbf{M}$ & SD & $\mathbf{M}$ & SD & $\mathbf{M}$ & SD & \\
\hline Sedentary behavior ( $\min /$ day) & 453.0 & 67.9 & 453.2 & 66.4 & 452.7 & 70.3 & 0.960 \\
\hline \multicolumn{8}{|l|}{ Physical activity (min/day) } \\
\hline Light & 415.8 & 59.5 & 418.1 & 59.5 & 412.8 & 59.8 & 0.570 \\
\hline Moderate & 32.8 & 13.9 & 29.6 & 10.5 & 37.0 & 16.5 & 0.001 \\
\hline Vigorous & 7.9 & 7.8 & 6.8 & 9.3 & 5.7 & 9.6 & 0.055 \\
\hline Moderate and vigorous & 40.7 & 20.0 & 36.3 & 15.0 & 46.1 & 23.9 & 0.002 \\
\hline \multicolumn{8}{|l|}{ Sleep } \\
\hline Amount of sleep (min/day) & 514.0 & 42.2 & 516.9 & 46.0 & 510.5 & 3.9 & 0.324 \\
\hline Nocturnal awakenings (n) & 7.8 & 3.7 & 8.0 & 3.6 & 7.5 & 3.2 & 0.399 \\
\hline
\end{tabular}

Results expressed as arithmetic mean (M), standard deviation (SD), and percentage. Student's t test or Mann-Whitney U test, as applicable. BMI: body mass index.

TABLE 3. Compliance with physical activity and sleep recommendations measured by accelerometry in a sample of 9 to 13year old school children from the city of Temuco, Chile $(n=183)$

\begin{tabular}{|c|c|c|c|c|c|c|}
\hline & \multicolumn{2}{|c|}{ Total } & \multicolumn{4}{|c|}{ By sex } \\
\hline & \multirow[t]{2}{*}{$\mathbf{n}$} & \multirow[t]{2}{*}{$\%$} & \multicolumn{2}{|c|}{ Girls } & \multicolumn{2}{|c|}{ Boys } \\
\hline & & & $\mathbf{n}$ & $\%$ & $\mathbf{n}$ & $\%$ \\
\hline \multicolumn{7}{|c|}{ Compliance with physical activity recommendations } \\
\hline Non-compliance & 140 & 85.4 & 84 & 92.3 & 56 & 76.7 \\
\hline Compliance & 24 & 14.6 & 7 & 7.7 & 17 & 23.3 \\
\hline \multicolumn{7}{|c|}{ Compliance with sleep recommendations } \\
\hline Non-compliance & 124 & 75.6 & 64 & 71.1 & 60 & 81.1 \\
\hline Compliance & 40 & 24.4 & 26 & 28.9 & 14 & 18.9 \\
\hline \multicolumn{7}{|c|}{ Compliance with both recommendations } \\
\hline Non-compliance with both & 123 & 68.3 & 68 & 68.6 & 55 & 67.0 \\
\hline Compliance with one & 52 & 28.9 & 29 & 29.2 & 23 & 28.0 \\
\hline Compliance with both & 6 & 2.8 & 2 & 2.2 & 4 & 5.0 \\
\hline
\end{tabular}


observed between compliance with sleep recommendations and the probability of having excess weight (Table 5).

\section{DISCUSSION}

The objective of this study was to determine the association between compliance with physical activity and sleep recommendations, as measured with accelerometers, and excess weight among school children from Temuco, Chile. In relation to physical activity levels, the total time spent doing physical activity by the study participants was lower than what has been observed in children with a similar age in Canada (58 min/day) and Australia (65 min/day), but close to that observed in India (48 min/ day) and Brazil (44 min/ day)..$^{32}$ In relation to sex, boys did almost 10 minutes more of moderate and vigorous physical activity than girls; this is consistent with several studies that suggested that boys are more active than girls. ${ }^{33,34}$ These results may be explained, in part, by biological factors, including the structure of muscle cells induced by sex hormones, ${ }^{35}$ as well as the differences in motor competence, for which boys show better performance levels. ${ }^{36}$

In relation to the amount of sleep, participants slept for a mean of 8.5 hours per day, being lower than those reported in children from Australia (9.4 hours) and Canada (9.1 hours), but similar to what has been observed in school children from

TABLE 4. Anthropometric, physical activity, and sleep characteristics by excess weight in a sample of school children from the city of Temuco, Chile $(n=183)$

\begin{tabular}{|c|c|c|c|c|c|}
\hline & \multicolumn{4}{|c|}{ Excess weight } & \multirow[b]{3}{*}{$p$} \\
\hline & \multicolumn{2}{|c|}{$\begin{array}{c}\text { Presence } \\
(n=69)\end{array}$} & \multicolumn{2}{|c|}{$\begin{array}{c}\text { Absence } \\
(\mathrm{n}=80)\end{array}$} & \\
\hline & $\mathbf{M}$ & SD & $\mathbf{M}$ & SD & \\
\hline Age (years) & 10.9 & 0.63 & 11.1 & 0.66 & 0.152 \\
\hline Weight (kg) & 51.3 & 9.24 & 38.2 & 5.79 & 0.000 \\
\hline Height $(\mathrm{cm})$ & 145.7 & 7.59 & 144.2 & 6.98 & 0.229 \\
\hline BMI & 24.1 & 2.90 & 18.3 & 1.70 & 0.000 \\
\hline Sedentary behavior (min/day) & 458.4 & 65.33 & 448.4 & 71.86 & 0.404 \\
\hline \multicolumn{6}{|l|}{ Physical activity (min/day) } \\
\hline Light & 418.3 & 59.67 & 413.2 & 60.39 & 0.627 \\
\hline Moderate & 29.1 & 10.67 & 34.8 & 14.84 & 0.013 \\
\hline Vigorous & 5.3 & 5.52 & 9.2 & 8.41 & 0.002 \\
\hline Moderate and vigorous & 34.4 & 13.56 & 43.8 & 22.01 & 0.004 \\
\hline \multicolumn{6}{|l|}{ Sleep } \\
\hline Amount of sleep (min/night) & 505.8 & 45.37 & 524.6 & 37.59 & 0.010 \\
\hline Nocturnal awakenings (n) & 4.0 & 0.46 & 3.7 & 0.43 & 0.105 \\
\hline
\end{tabular}

Results expressed as arithmetic mean (M) and standard deviation (SD).

Student's t test or Mann-Whitney U test, as applicable. BMI: body mass index.

TABLE 5. Adjusted logistic regression model to predict excess weight based on compliance with physical activity and sleep recommendations

\begin{tabular}{|c|c|c|c|c|}
\hline & \multirow[t]{2}{*}{ OR } & \multicolumn{2}{|c|}{$95 \% \mathrm{CI}$} & \multirow[b]{2}{*}{$p$} \\
\hline & & Lower & Upper & \\
\hline Age & 0.827 & 0.441 & 1.550 & 0.553 \\
\hline Sex & 2.242 & 0.942 & 5.335 & 0.068 \\
\hline Sedentary time & 1.000 & 0.995 & 1.006 & 0.891 \\
\hline Non-compliance with physical activity recommendations & 8.178 & 1.465 & 45.635 & 0.017 \\
\hline Non-compliance with sleep recommendations & 1.297 & 0.512 & 3.287 & 0.584 \\
\hline
\end{tabular}

Model adjusted by age, sex, and sedentary behavior time. OR: odds ratio; CI: confidence interval. 
Brazil (8.8 hours), China (8.5 hours), and India (8.6 hours). ${ }^{32}$ Girls' values were slightly higher than those of boys, but this difference was not statistically significant; this is consistent with the results obtained by Toledo-Vargas et al. ${ }^{22}$ Other studies have reported that boys sleep more, ${ }^{37}$ so the role of sex on the amount of sleep in the pediatric population is still not clearly defined.

In our study, only $14.6 \%$ of participants complied with physical activity recommendations. Compliance was low when compared to the boys and girls from countries like Australia (55\%), Brazil (44\%) or Canada (44\%), but similar to what has been observed in China (15\%). ${ }^{33}$ In relation to sleep recommendations, only $24.4 \%$ of participants met them; this proportion is lower than that observed in other studies done in Chilean school children ${ }^{22,26}$ and than those observed in other countries, like Australia (75\%) and Canada (58\%), but similar to that of Brazil $(24 \%){ }^{32}$ The assessment of the percentage of the sample that met both physical activity and sleep recommendations found a much lower proportion: $2.8 \%$. Such extremely low compliance levels are similar to those reported by ToledoVargas et al., ${ }^{22}$ which puts Chile in a critical situation due to a high percentage of school children at a higher risk for excess weight.

The analysis of physical activity time and amount of sleep based on the presence or absence of excess weight showed that school children without excess weight did almost 9 minutes more of moderate and vigorous physical activity than those with excess weight, and this is in line with the evidence found in other studies. ${ }^{37,38}$

In addition, school children without excess weight slept almost 20 minutes more per day than those with excess weight; these results are similar to those obtained by Ruiz et al. ${ }^{39}$ These results are consistent with the emerging tendency about the relationship among physical activity, amount of sleep, and nutritional status, which indicates that a longer and more stable sleep time leads to a child with less probabilities of developing metabolic disorders. ${ }^{17}$

The assessment of the association between compliance with moderate to vigorous physical activity and sleep recommendations and the presence of excess weight showed that school children who do not meet the physical activity recommendations have a higher probability of developing excess weight than those who do, similar to what has been reported by RomanViñas et al., ${ }^{40}$ and Katzmarzyk et al. ${ }^{25}$ In addition, no association was observed between compliance with sleep recommendations and the presence of excess weight. Although our study found significant differences in the amount of sleep between normal and excess weight school children, a large number of them -regardless of their weight status- did not comply with sleep recommendations, which may explain the lack of association; therefore, such difference indicates the need to study this topic more in depth.

One of the study strengths that is worth noting is the use of accelerometers, which allow to assess both physical activity and sleep levels in a more accurate manner. In addition, one of the limitations of this study is that, considering that it has a crosssectional design, it is not possible to establish the causality of these results. Similar to what has been observed in another study conducted in the same region of Chile, ${ }^{22}$ two thirds of the sample considered in the beginning completed the protocol for inclusion in the final analysis; however, the minimum estimated sample size was not reached. Another limitation was that school children's eating habits were not recorded, which may have an effect on results. Also, week days and weekends were not analyzed separately, and the different year periods were not measured, which may have provided additional information about physical activity behavior and the amount of sleep in school children.

\section{CONCLUSIONS}

Compliance with physical activity and sleep recommendations in our study sample is low. Boys do more moderate and vigorous physical activity than girls, whereas school children with excess weight show lower physical activity levels than their normal weight peers. In relation to the amount of sleep, no significant differences were observed between males and females, but, in terms of weight, school children with excess weight sleep less time. Non-compliance with physical activity recommendations may be associated with excess weight. No association was observed between compliance with sleep recommendations and the presence of excess weight.

\section{REFERENCES}

1. Broyles S, Katzmarzyk PT, Srinivasan SR, Chen W, et al. The pediatric obesity epidemic continues unabated in Bogalusa, Louisiana. Pediatrics. 2010; 125(5):900-5.

2. Kumar S, Kaufman T. Childhood obesity. Panminerva Med. 2018; 60(4):200-12.

3. Mönckeberg BF, Muzzo BS. La desconcertante epidemia de obesidad. Rev Chil Nutr. 2015; 42(1):96-102. 
4. Myers A, Gibbons C, Finlayson G, Blundell J. Associations among sedentary and active behaviours, body fat and appetite dysregulation: investigating the myth of physical inactivity and obesity. Br J Sports Med. 2017; 51(21):1540-4.

5. Aguilar-Farias N, Martino-FuentealbaP,Carcamo-Oyarzun J, Cortinez-O'Ryan A, et al. A regional vision of physical activity, sedentary behaviour and physical education in adolescents from Latin America and the Caribbean: results from 26 countries. Int J Epidemiol. 2018; 47(3):976-86.

6. Berglind D, Tynelius P. Objectively measured physical activity patterns, sedentary time and parent-reported screen-time across the day in four-year-old Swedish children. BMC Public Health. 2018; 18(1):69.

7. Alvarez-Pitti J, Casajús Mallén J, Leis Trabazo R, Lucía A, et al. Ejercicio físico como «medicina» en enfermedades crónicas durante la infancia y la adolescencia. An Pediatr (Barc). 2020; 92(3):173.e1-8.

8. Ip P, Ho F, Louie L, Chung T, et al. Childhood obesity and physical activity-friendly school environments. J Pediatr. 2017; 191:110-6.

9. Delgado-Floody P, Caamaño-Navarrete F, Jerez-Mayorga D, Cofré-Lizama A, et al. Obesidad, autoestima y condición física en escolares. Rev Fac Med. 2017; 65(1):43-8.

10. Messerli-Bürgy N, Horsch A, Schindler C, Boichat A, et al. Influence of Acute Physical Activity on Stress Reactivity in Obese and Normal Weight Children: A Randomized Controlled Trial. Obes Facts. 2019; 12(1):115-30.

11. Bedard C, HannaS, Cairney J. A longitudinal study of sport participation and perceived social competence in youth. $J$ Adolesc Health. 2020; 66(3):352-9.

12. Bidzan-Bluma I, Lipowska M. Physical activity and cognitive functioning of children: a systematic review. Int J Environ Res Public Health. 2018; 15(4):800.

13. Barnett LM, Salmon J, Hesketh KD. More active pre-school children have better motor competence at school starting age: an observational cohort study. BMC Public Health. 2016; 16(1):1068.

14. Iglesias A, Planells E, Molina López J. Prevalencia de sobrepeso y obesidad, hábitos alimentarios y actividad física y su relación sobre el rendimiento académico. Retos. 2019; 36:167-73.

15. Chaput JP, Brunet M, Tremblay A. Relationship between short sleeping hours and childhood overweight/obesity: results from the 'Quebec en Forme' Project. Int JObes (Lond). 2006; 30(7):1080-5.

16. Knutson KL, Spiegel K, Penev P, Van Cauter E. The metabolic consequences of sleep deprivation. Sleep Med Rev. 2007; 11(3):163-78.

17. Spruyt K, Molfese DL, Gozal D. Sleep duration, sleep regularity, body weight, and metabolic homeostasis in school-aged children. Pediatrics. 2011; 127(2):e345-52.

18. Matricciani L, Olds T, Petkov J. In search of lost sleep: secular trends in the sleep time of school-aged children and adolescents. Sleep Med Rev. 2012; 16(3):203-11.

19. Tremblay M, Carson V, Chaput J, Connor Gorber S, et al. Canadian 24-hour movement guidelines for children and youth: an integration of physical activity, sedentary behaviour, and sleep. Appl Physiol Nutr Metab. 2016; 41 (6 Suppl 3):S311-27.

20. Tremblay M, Carson V, Chaput J. Introduction to the Canadian 24-Hour Movement Guidelines for Children and Youth: An Integration of Physical Activity, Sedentary Behaviour, and Sleep. Appl Physiol Nutr Metab. 2016; 41 (6 Suppl 3):iii-iv.

21. World Health Organization. WHO Guidelines on physical activity and sedentary behaviour, 2020. [Accessed on: March 3 $3^{\text {rd }}$ 2021]. Available at: https:/ / www.who.int/ publications/i/item/9789240015128

22. Toledo-Vargas M, Perez-Contreras P, Chandia-Poblete D, Aguilar-Farias N. Compliance of the 24-Hour Movement Guidelines in 9- to 11-Year-Old Children From a LowIncome Town in Chile. J Phys Act Health. 2020; 17(10):103441.

23. Aguilar M, Vergara FA, Velásquez E, García-Hermoso A. Actividad física, tiempo de pantalla y patrones de sueño en niñas chilenas. An Pediatr (Barc). 2015; 83(5):304-10.

24. Aguilar-Farias N, Miranda-Marquez S, Sadarangani KP, Martino-Fuentealba P, et al. Results from Chile's 2018 report card on physical activity for children and youth. J Phys Act Health. 2018; 15(Suppl 2):S331-2.

25. KatzmarzykPT, Staiano AE. Relationship between meeting 24-hour movement guidelines and cardiometabolic risk factors in children. J Phys Act Health. 2017; 14(10):779-84.

26. Duran AS, Fuentes de la CN, Vásquez QS, Cediel GG, et al. Relación entre estado nutricional y sueño en escolares de la comuna de San Miguel, Santiago, Chile. Rev Chil Nutr. 2012; 39(1):30-7.

27. Williamson DA, Champagne CM, Harsha DW, Han H, et al. Effect of an environmental school $\square$ based obesity prevention program on changes in body fat and body weight: a randomized trial. Obesity (Silver Spring). 2012; 20(8):1653-61.

28. Tudor-Locke C, Barreira T, Schuna J Jr. Comparison of step outputs for waist and wrist accelerometer attachment sites. Med Sci Sports Exerc. 2015; 47(4):839-42.

29. Sadeh A, Acebo C. The role of actigraphy in sleep medicine. Sleep Med Rev. 2002; 6(2):113-24.

30. Evenson K, Catellier D, Gill K, Ondrak K, et al. Calibration of two objective measures of physical activity for children. J Sports Sci. 2008; 26(14):1557-65.

31. World Health Organization. Growth reference data for 5-19 years. BMI for age (5-19 years), 2013. [Accessed on: March $\left.3^{\text {rd }}, 2021\right]$. Available at: https://www.who.int/ tools / growth-reference-data-for-5to19-years / indicators / bmi-for-age

32. Thivel D, Tremblay M, Katzmarzyk P, Fogelholm M, et al. Associations between meeting combinations of 24hour movement recommendations and dietary patterns of children: A 12-country study. Prev Med. 2019; 118:159-65.

33. Glinkowska B, Glinkowski W. Association of sports and physical activity with obesity among teenagers in Poland. Int J Occup Med Environ Health. 2018; 31(6):771-82.

34. Gutierrez-Hervas A, Cortés-Castell E, Juste-Ruíz M, RizoBaeza M. ¿Qué variables influyen en el cumplimiento de las recomendaciones de actividad física en preescolares? An Pediatr (Barc). 2020; 92(3):156-64.

35. Wang WY, Hsieh YL, Hsueh MC, Liu Y, etal. Accelerometermeasured physical activity and sedentary behavior patterns in Taiwanese adolescents. Int J Environ Res Public Health. 2019; 16(22):4392.

36. Carcamo-Oyarzun J, Estevan I, Herrmann C. Association between Actual and Perceived Motor Competence in School Children. Int J Environ Res Public Health. 2020; 17(10):3408.

37. Harrex H, Skeaff S, Black K, Davison B, et al. Sleep timing is associated with diet and physical activity levels in 9-11-year $\square$ old children from Dunedin, New Zealand: the PEDALS study. J Sleep Res. 2018; 27(4):e12634.

38. PereiraS, Katzmarzyk P, Gomes T, Borges A, et al. Profiling physical activity, diet, screen and sleep habits in Portuguese children. Nutrients. 2015; 7(6):4345-62. 
39. RuizN, Rangel A, Rodríguez C, Rodríguez L, et al. Relación entre el déficit de sueño nocturno, el exceso de peso y las alteraciones metabólicas en adolescentes. Arch Argent Pediatr. 2014; 112(6):511-8.
40. Roman-Viñas B, Chaput JP, Katzmarzyk PT, Fogelholm $\mathrm{M}$, et al. Proportion of children meeting recommendations for 24-hour movement guidelines and associations with adiposity in a 12-country study. Int J Behav Nutr Phys Act. 2016; 13(1):123. 